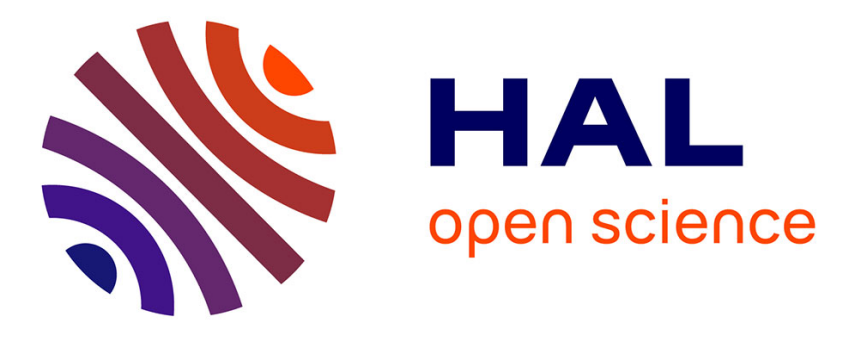

\title{
Attention Deficits in Alzheimer's Disease and Vascular Dementia
}

Bernadette Mcguinness, Suzanne L Barrett, David Craig, John Lawson, Peter

Passmore

\section{- To cite this version:}

Bernadette Mcguinness, Suzanne L Barrett, David Craig, John Lawson, Peter Passmore. Attention Deficits in Alzheimer's Disease and Vascular Dementia. Journal of Neurology, Neurosurgery and Psychiatry, 2010, 81 (2), pp.157. 10.1136/jnnp.2008.164483 . hal-00552734

\section{HAL Id: hal-00552734 https://hal.science/hal-00552734}

Submitted on 6 Jan 2011

HAL is a multi-disciplinary open access archive for the deposit and dissemination of scientific research documents, whether they are published or not. The documents may come from teaching and research institutions in France or abroad, or from public or private research centers.
L'archive ouverte pluridisciplinaire HAL, est destinée au dépôt et à la diffusion de documents scientifiques de niveau recherche, publiés ou non, émanant des établissements d'enseignement et de recherche français ou étrangers, des laboratoires publics ou privés. 
Title: Attention Deficits in Alzheimer's Disease and Vascular Dementia

Authors: McGuinness $\mathrm{B}^{1}$, Barrett $\mathrm{SL}^{2}$, Craig $\mathrm{D}^{1}$, Lawson $\mathrm{J}^{3}$, Passmore $\mathrm{AP}^{1}$

Affiliations: 'Department of Geriatric Medicine Queen's University Belfast, Belfast, UK

²Department of Mental Health, Queen's University Belfast, Belfast, UK

${ }^{3}$ Radiology Department, Belfast City Hospital, Belfast, UK

\author{
Correspondence to: Dr B McGuinness \\ Department of Geriatric Medicine \\ Whitla Medical Building \\ 97 Lisburn Road \\ Belfast BT9 7BL. \\ Tel +44(0) 2890975777 \\ Fax +44 (0) 2890325839 \\ Email: b.mcguinness@qub.ac.uk
}

Disclosure of Conflicts of Interest: None 
Word Count 1491

Abstract: 156 words

Figures: $\mathbf{n}=0$

Tables: $n=1$

References: $\mathbf{n = 2 2}$

The Corresponding Author has the right to grant on behalf of all authors and does grant on behalf of all authors, an exclusive licence (or non-exclusive for government employees) on a worldwide basis to the BMJ Publishing Group Ltd and its Licensees to permit this article (if accepted) to be published in Journal of Neurology, Neurosurgery \& Psychiatry and any other BMJPGL products to exploit all subsidiary rights, as set out in our licence (http://jnnp.bmi.com/ifora/licence.pdf). 


\section{Abstract}

Objective: To compare performance of patients with mild-moderate Alzheimer's disease (AD) and Vascular Dementia $(\mathrm{VaD})$ on tests of information processing and attention.

Method: Patients with $A D(n=75)$ \& $\operatorname{VaD}(n=46)$ were recruited from a memory clinic along with dementia-free participants $(n=28)$. They underwent specific tests of attention from the Cognitive Drug Research (CDR) battery and pen and paper tests including Colour Trails A and B and Stroop. All patients had a CT brain scan which was independently scored for white matter change/ischaemia.

Results: Attention was impaired in both $\mathrm{AD}$ and $\mathrm{VaD}$ patients. $\mathrm{VaD}$ patients had more impaired choice reaction times and were less accurate on a vigilance test measuring sustained attention. Deficits in selective and divided attention occurred in both patient groups and showed the strongest correlations with MMSE scores.

Conclusion: This study demonstrates problems with the attentional network in mild-moderate AD and VaD. We propose attention should be tested routinely in a memory clinic setting.

Keywords: attention, Alzheimer's Disease, information processing, reaction time, Vascular Dementia 


\section{Introduction}

The precise nature of neuropsychological deficits in Alzheimer's disease (AD) and Vascular Dementia (VaD) has been the subject of intense investigation over recent years. In accordance with neuropathological findings (1-2), one might expect an initial amnestic syndrome in AD, with impairments in other cognitive domains (e.g. attention) arising as the disease progresses. In contrast, one would expect an excess of frontal executive dysfunction, attention changes, behavioural disinhibition and apathy in $\mathrm{VaD}$, with or without memory impairments from an early stage.

With respect to attention, previous studies have supported this dissociation, with VaD patients showing greater attentional deficits compared to AD patients (3-4). However, there have been inconsistencies: other studies show equal impairments in both diagnoses (5-6). This issue is important as poor performance on measures of selective and divided attention in early $A D$ may reflect greater pathology in frontal lobes and associated areas, and/or corticocortical tract disconnection, than would be anticipated (7).There are a range of factors that may explain this lack of consensus across studies: modest sample sizes and differences between cohorts in patients' duration of illness. Furthermore, attention is commonly tested as part of a multi-domain cognitive battery: the predominant approach is to comparatively examine one aspect of attention, with this aspect often varying across studies. 
The aim of the following study was to examine information processing speed, selective, divided and sustained attention in patients with mild-moderate $\mathrm{AD}$ and $\mathrm{VaD}$.

\section{Methods}

The Research Ethics Committee of Queens University Belfast approved this cohort study (Application Number 249/03). Written informed consent was obtained from all participants and assent from carers if necessary. Patients (VaD $n=46 ; A D$ $n=75$ ) and a dementia-free comparison group (DF $n=28$ ) were recruited from the memory clinic at the Belfast City Hospital. The latter presented as patients (i.e. the 'worried well') or spouses of patients. They had no evidence of cognitive impairment (Mini Mental State Examination [MMSE] >28 [8]) or depression on detailed questioning.

A diagnosis of probable AD and probable VaD was made using the NINCDS-ADRDA (9) and NINDS AIREN (10) criteria respectively. Only patients with MMSE $\geq 12$ were included as we were primarily interested in patients with mild-moderate disease.

Patients with other forms of dementia, depression (as indicated by a score $>10$ on the Geriatric Depression Scale (GDS) [11]) and/or on psychotropic drugs that could impair attention were excluded. An experienced radiologist blinded to patients' clinical diagnosis quantified the site and severity of white matter changes and cerebrovascular disease on CT images available ( $n=127)$ using the White Matter Scale [WMS] (12) and an adapted Image Criteria Score [alCS] (13). 


\section{Neuropsychological Evaluation}

Premorbid IQ was estimated using the National Adult Reading Test [NART] (14). Participants were assessed for Simple Reaction Time [SRT], Choice Reaction Time [CRT], and Digit Vigilance [DVT] (measures sustained attention over time) using the Cognitive Drug Research [CDR] computerized cognitive assessment system (15). Measures of information processing speed, response accuracy and false alarm rate were recorded as appropriate. One composite measure, Reaction Time Variability, was also derived from these three tasks. This assessed consistency of response and reflects fluctuations in attention. Three paper and pencil tests were used to assess divided and sustained attention: Colour Trails [CT] A \& Colour Trails [CT] B (16) and the Stroop Test (17). CT-A primarily involves perceptual tracking and simple sequencing. CT-B is a test of executive divided attention and sequencing. It more directly assesses frontal systems functioning than CT-A due to the alternating sequence pattern. The Stroop test primarily measures executive selective attention as the participant must ignore the distraction of the non-congruent colour words during the test phase.

\section{Statistical Analysis}

Data were analysed using SPSS Version 14 (Chicago, IL, 2007). Demographic data were compared using one-way analysis of variance [ANOVA]. Missing neurocognitive data $(<5 \%)$ were imputed using the expectation-maximization method. Data was missing at random and did not differ between groups. Group differences on tests of attention were then 
compared using Analysis of Covariance [ANCOVA] and Bonferroni corrected post-hoc multiple comparisons. Covariates considered in these models were age and years of education. Gender had no significant main effect nor did it interact with group so was not retained in ANCOVA models. The relationships between attention tests and MMSE were examined using Pearson's correlations. Radiological scores were compared using Mann Whitney U. 


\section{$\underline{\text { Results }}$}

$A D$ and $\operatorname{VaD}$ patients did not significantly differ in terms of age $(A D=77.7 \pm 6.9$ years; $V a D=75.9 \pm 7.8$ years), sex ( $F: M$ 52:24 $\left.A D ; 24: 22 \mathrm{VaD}, \mathrm{x}^{2}=3.3, \mathrm{p}=0.14\right)$, years of education $(\mathrm{AD}=11.3 \pm 2.4 ; \mathrm{VaD}=11.2 \pm 2.3)$; and $\mathrm{NART} I \mathrm{Q}(\mathrm{AD}=109.4 \pm 8.4$; $\mathrm{VaD}=109.6 \pm 9.1$ ). Despite best efforts to match patients and the DF group, there was a significant difference between both disease groups and the DF group in terms of age ( $D F=70.2 \pm 7.9$ years; $p<0.01)$, years of education ( $D F=13.6 \pm 3.4$; $\mathrm{p}=0.01)$, and NART IQ $(\mathrm{DF}=119.6 \pm 7.6 ; \mathrm{p}<0.01)$. Analysis of radiological scores revealed significantly more cerebrovascular disease in the $\mathrm{VaD}$ group compared to $\mathrm{AD}$ patients $(\mathrm{p}<0.01)$.

Results from attentional measures are shown in Table 1. Information processing speed (SRT, CRT and DVT) was significantly slower in patients compared to the DF group $(p<0.01)$, reaction times were also more variable in patients $(p<0.01)$. The $\mathrm{VaD}$ group had significantly slower CRT compared to the AD group $(p<0.05)$. This remained significant when SRT was added as a covariate to the analysis $(p<0.01)$. Accuracy was maintained by patients on the CRT. However, the $\mathrm{VaD}$ group was less accurate than the DF $(p<0.01)$ and $A D(p<0.05)$ groups on the DVT.

Patients were impaired on both CT-A and CT-B, as well as on all stages of the Stroop compared to the DF group $(p<0.01)$, but no differences were observed between the $A D$ and $\mathrm{VaD}$ groups. Group differences on CT-B remained 
significant after covarying for performance on CT-A $(p<0.01)$. Findings for the test phase of the Stroop also remained significant after covarying for simple word naming $(p=0.02)$ and simple colour naming $(p<0.01)$ performance.

In the AD group, there were no significant correlations between MMSE and processing speed measures (SRT, CRT, DVT: $r<0.2)$ nor with accuracy on the CRT or DVT $(r<0.15)$. MMSE correlated significantly with DVT false alarms $(r=0.24$, $p=0.04)$, Reaction Time Variability $(r=-0.25, p=0.03)$, CT-A $(r=-0.29, p=0.02)$, CT-B $(r=-0.32, p=0.01)$ and the Stroop $(r=0.48, p<0.01)$. In the VaD group, there was no significant correlation between MMSE and any measure from the CDR battery (SRT r=-0.25; CRT r=-0.21, CRT accuracy, DVT false alarms, Reaction Time Variability, DVT accuracy: $r<0.15$ ) apart from DVT reaction time $(r=-0.38, p=0.01)$. However, correlations between MMSE and CT-A $(r=-0.35, p=0.03)$; CT-B $(r=-0.46, p<0.01)$ and Stroop $(r=0.49, p<0.01)$ were statistically significant. The pattern of correlations remained unchanged when education was co-varied for. 


\section{Discussion}

In this study, we compared information processing speed and attention in patients with mild-moderate $A D$ and VaD. Information processing speed was more impaired in both patient groups and also lacked consistency over time. Decision making/thinking time [i.e. CRT] was more impaired in mild-moderate VaD. Despite the observed impairments in information processing speed, accuracy of responding on the CRT was unimpaired in both patient groups, which is suggestive of a speed/accuracy trade-off. This has been demonstrated previously in an AD cohort (18).

The literature suggests sustained attention is affected late in the progression of AD (7). Results from the DVT would both support and extend this assertion: in contrast to patients with $A D$, sustained attention is impaired at an early stage in VaD patients. Divided attention [i.e. CT-B] and selective attention [i.e. Stroop] were impaired in both patient groups, which is suggestive of greater frontal lobe impairment in early AD than would necessarily be expected. Previous studies have shown deficits in divided attention in early AD (19-20) but the literature specific to $\mathrm{VaD}$ is scant. One previous study reported impaired performance on this task in both diagnostic groups ( $A D n=37, \operatorname{VaD} n=31$ ) but no significant difference between the diagnoses (21). However, impaired performance on the CT-A test would indicate that poor perceptual tracking and simple sequencing is a likely contributor to the observed deficits in divided attention. Impaired Stroop performance has been demonstrated before in mild-moderate dementia (22). However, impaired performance on the simple word and colour naming tasks would indicate that impaired information processing speed is a likely contributor to 
most of the observed deficits in selective attention in these patients. Performance on both the CT-B and Stroop correlated most strongly with MMSE in both $\mathrm{AD}$ and $\mathrm{VaD}$ groups suggesting a relationship between impairments in divided and selective attention and disease progression, albeit from cross-sectional data.

Limitations of the study include the fact that the control group was significantly younger and better educated than the disease group. However, this was controlled for in statistical analyses. In comparing AD and VaD patients it is always difficult to ensure the 'pure' phenotype of each is included. Recognized rating scales were used to quantify white matter change and vascular lesions on CT to support diagnostic criteria. MRI would have been preferable but was not available routinely.

In conclusion we found deficits in processing speed and attention in mild-moderate $A D$ and $\mathrm{VaD}$ and propose these domains are measured routinely in a clinic setting.

Acknowledgements: We would like to thank Keith Wesnes and Brain Saxby from CDR for collaboration and advice on statistical analysis. 


\section{$\underline{\text { References }}$}

1 Tomlinson, B. E., Blessed, G. and Roth, M. (1970) Observations on the Brains of Demented Old People. J. Neurol. Sci. $11,205-242$

2 Braak, H. and Braak, E. (1991) Neuropathological Staging of Alzheimer-Related Changes. Acta Neuropathol. (Berl). $82,239-259$

3 Mendez, M. F. and Ashla-Mendez, M. (1991) Differences between Multi-Infarct Dementia and Alzheimer's Disease on Unstructured Neuropsychological Tasks. J. Clin. Exp. Neuropsychol. 13, 923-932

4 Almkvist, O., Backman, L., Basun, H. and Wahlund, L. O. (1993) Patterns of Neuropsychological Performance in Alzheimer's Disease and Vascular Dementia. Cortex. 29, 661-673

5 Loring, D. W., Meador, K. J., Mahurin, R. K. and Largen, J. W. (1986) Neuropsychological Performance in Dementia of the Alzheimer Type and Multi-Infarct Dementia. Arch. Clin. Neuropsychol. 1, 335-340

6 Mazzucchi, A., Capitani, E., Poletti, A., Posteraro, L., Bocelli, G., Campari, F. and Parma, M. (1987) Discriminant Analysis of WAIS Results in Different Types of Dementia and Depressed Patients. Funct. Neurol. 2, 155-163

7 Perry, R. J. and Hodges, J. R. (1999) Attention and Executive Deficits in Alzheimer's Disease. A Critical Review. Brain. 122 ( Pt 3), 383-404

8 Folstein, M. F., Folstein, S. E. and McHugh, P. R. (1975) 'Mini-Mental State'. A Practical Method for Grading the Cognitive State of Patients for the Clinician. J Psychiatr Res. 12, 189-198

9 McKhann, G., Drachman, D., Folstein, M., Katzman, R., Price, D. and Stadlan, E. (1984) Clinical Diagnosis of Alzheimer's Disease: Report of the NINCDS-ADRDA Work Group under the Auspices of Department of Health and Human Services Task Force on Alzheimer's Disease. Neurology. 34, 939-944 
10 Roman, G. C., Tatemichi, T. K., Erkinjuntti, T., Cummings, J. L., Masdeu, J. C., Garcia, J. H., Amaducci, L., Orgogozo, J. M., Brun, A. and Hofman, A. (1993) Vascular Dementia: Diagnostic Criteria for Research Studies. Report of the NINDS-AIREN International Workshop. Neurology. 43, 250-260

11 Yesavage, J. A. (1988) Geriatric Depression Scale. Psychopharmacol. Bull. 24, 709-711

12 van Swieten, J. C., Hijdra, A., Koudstaal, P. J. and van Gijn, J. (1990) Grading White Matter Lesions on CT and MRI: A Simple Scale. J. Neurol. Neurosurg. Psychiatry. 53, 1080-1083

13 Pullicino, P., Benedict, R. H., Capruso, D. X., Vella, N., Withiam-Leitch, S. and Kwen, P. L. (1996) Neuroimaging Criteria for Vascular Dementia. Arch. Neurol. 53, 723-728

14 Nelson, H. E. and O'Connell, A. (1978) Dementia: The Estimation of Premorbid Intelligence Levels using the New Adult Reading Test. Cortex. 14, 234-244

15 www.cognitivedrugresearch.com

16 D'Elia, L.F., Satz, P., Uchiyama, C.L. and White T., 1996. Color Trails Test. Professional manual, Psychological Assessment Resources, Odessa, FL.

17 Golden, C. (1978) Stroop Color and Word Test Manual (cat. 30150M). Chicago: Stoelting Co.

18 Nicholl, C. G., Lynch, S., Kelly, C. A., White, L., Simpson, P. M., Wesnes, K. A. and Pitt, B. M. N. (1995) The Cognitive Drug Research Computerized Assessment System in the Evaluation of Early Dementia-is Speed of the Essence? International Journal of Geriatric Psychiatry. 10, 199-206

19 Binetti, G., Magni, E., Padovani, A., Cappa, S. F., Bianchetti, A. and Trabucchi, M. (1996) Executive Dysfunction in Early Alzheimer's Disease. J. Neurol. Neurosurg. Psychiatry. 60, 91-93 
20 Lafleche, G. and Albert, M. S. (1995) Executive Function Deficits in Mild Alzheimer's Disease. Neuropsychology. 9, 313-320

21 Barr, A., Benedict, R., Tune, L. and Brandt, J. (1992) Neuropsychological Differentiation of Alzheimer's Disease from Vascular Dementia. Int J Geriatr Psychiatry. 7, 621-627

22 Bondi, M. W., Serody, A. B., Chan, A. S., Eberson-Shumate, S. C., Delis, D. C., Hansen, L. A. and Salmon, D. P. (2002) Cognitive and Neuropathologic Correlates of Stroop Color-Word Test Performance in Alzheimer's Disease.

Neuropsychology. 16, 335-343 
Table 1: Comparisons between Groups on Tests of Attention

\begin{tabular}{|c|c|c|c|c|c|c|c|c|c|c|}
\hline \multirow[t]{2}{*}{ Attention Parameter } & \multicolumn{2}{|c|}{$\begin{array}{l}\text { Controls } \\
n=28\end{array}$} & \multicolumn{2}{|c|}{$\begin{array}{l}\text { AD } \\
n=75\end{array}$} & \multicolumn{2}{|c|}{$\begin{array}{l}\text { VaD } \\
n=46\end{array}$} & \multicolumn{4}{|c|}{ ANCOVA } \\
\hline & Mean & SD & Mean & SD & Mean & SD & $\mathrm{F}$ & df & $p$ & Multiple Comparisons \\
\hline Simple Reaction Time (milliseconds) & 348.3 & $(90)$ & 520.5 & (207) & 518.9 & $(232)$ & 4.6 & 2,146 & 0.01 & Con $<\mathrm{AD}^{*}, \mathrm{Con}<\mathrm{VaD}^{*}$ \\
\hline Choice Reaction Time (milliseconds) & 516.7 & $(64)$ & 638.2 & $(150)$ & 711.3 & $(208)$ & 8.9 & 2,146 & $<0.01$ & $\begin{array}{l}\text { Con }<A D^{*} \text {, Con }<V D^{* *} \\
A D<V_{a D}\end{array}$ \\
\hline Digit Vigilance Reaction Time (milliseconds) & 456.4 & $(56)$ & 548.0 & (89) & 559.0 & $(100)$ & 6.5 & 2,146 & $<0.01$ & Con $<A D^{*}$, Con $<V_{a} D^{* *}$ \\
\hline Reaction Time Variability $†$ & 0.55 & $(0.1)$ & 0.66 & $(0.2)$ & 0.71 & $(0.2)$ & 7.1 & 2,146 & $<0.01$ & Con $<\mathrm{AD}^{*}$, Con $<$ VaD* \\
\hline Choice Reaction Accuracy (\% correct) & 95.6 & $(4.9)$ & 95.3 & $(5.5)$ & 95.2 & $(4.4)$ & 0.1 & 2,146 & 0.95 & \\
\hline Digit Vigilance Accuracy (\% correct) & 97.5 & $(2.8)$ & 93.7 & $(10.6)$ & 89.1 & (15.8) & 6.3 & 2,146 & $<0.01$ & $A D>V a D^{*}$, Con $>V a D^{* *}$ \\
\hline Digit Vigilance False Alarms (number) & 1.9 & $(2.2)$ & 1.1 & $(1.8)$ & 1.7 & $(2.0)$ & 1.85 & 2,146 & 0.16 & \\
\hline Colour Trails A (seconds) & 57.1 & $(16)$ & 116.0 & $(59)$ & 115.2 & $(53.5)$ & 7.6 & 2,136 & $<0.01$ & Con $<\mathrm{AD}^{* *} ;$ Con $<\mathrm{VaD}^{* *}$ \\
\hline Colour Trails B (seconds) & 107.25 & $(35.1)$ & 220.9 & $(69.9)$ & 223.4 & (93.9) & 15.7 & 2,136 & $<0.01$ & Con $<\mathrm{AD}^{* *} ;$ Con $<\mathrm{VaD}{ }^{* *}$ \\
\hline Stroop Word Naming (n in 45 seconds) & 95.6 & $(15.1)$ & 73.2 & $(16.9)$ & 67.2 & $(20.0)$ & 11.9 & 2,135 & $<0.01$ & Con $>A D^{* *} ;$ Con $>V_{a} D^{* *}$ \\
\hline Stroop Colour Naming (n in 45 seconds) & 61.36 & $(10.5)$ & 43.5 & $(12.0)$ & 41.62 & $(14.3)$ & 8.5 & 2,135 & $<0.01$ & Con $>A D^{* *} ;$ Con $>V a D^{* *}$ \\
\hline Stroop Colour-Word Test ( $\mathrm{n}$ in 45 seconds) & 29.56 & $(8.5)$ & 17.2 & (8.3) & 15.8 & $(6.4)$ & 13.4 & 2,135 & $<0.01$ & Con $>A D^{* *} ;$ Con $>V a D^{* *}$ \\
\hline
\end{tabular}

*Significant $p<0.05 ;{ }^{*}$ Significant $p<0.01$

† Sum of coefficients of variance of speed scores from simple reaction time, choice reaction time and digit vigilance; reflects fluctuations in attention 
